\title{
Het oogonderzoek in de jeugdgezondheidszorg op de leeftijd van 3 jaar: ruimte voor verbetering
}

\author{
V. lyer (D) - A. van Samkar - E. Vlasblom - H. M. van Minderhout - S. van der Harst
}

Published online: 9 November 2017

(C) Bohn Stafleu van Loghum, onderdeel van Springer Media B.V. 2017

Samenvatting Achtergrond Nederlandse kinderen krijgen op de leeftijd van 36 maanden op het consultatiebureau een visustest aangeboden met behulp van de Amsterdamse Plaatjes Kaart (APK). Bij een afwijkende APK-uitslag is het mogelijk om een Vroegtijdige Opsporing van Visuele Stoornissen (VOV) onderzoek aan te bieden. Na verwijzing wordt in het ziekenhuis een uitgebreid oogonderzoek gedaan. Een alternatief voor de VOV zou de Brückner Test Variant (BTV) kunnen zijn. In dit onderzoek wordt nagegaan hoeveel kinderen onterecht verwezen worden naar aanleiding van de APK-testuitslag, of de VOV- en BTV-uitslagen onterechte verwijzingen kunnen voorkomen, en hoe de APK-test wordt uitgevoerd.

Methode Tussen oktober 2013 en januari 2014 werden kinderen met een afwijkende uitslag van de APK-test geselecteerd en werd hen een VOV- en BTV-onderzoek aangeboden. Deze resultaten werden vergeleken met het uitgebreide oogonderzoek in het ziekenhuis.

Resultaten Van de 1950 driejarigen had $21 \%$ een afwijkende score op de APK-test. Bij 1 op de 4 verwijzingen was een uitslag van het oogonderzoek in het ziekenhuis beschikbaar. Amblyopie, de aandoening waarop het onderzoek in de jeugdgezondheidszorg op de leef-

V. Iyer $(\bowtie) \cdot$ E. Vlasblom

Child Health, TNO, Leiden, Nederland

iyer.samkar@gmail.com

A. van Samkar

Afdeling Neurologie, Canisius-Wilhelmina Ziekenhuis,

Nijmegen, Nederland

H. M. van Minderhout

Afdeling Oogheelkunde, Medisch Centrum Haaglanden, Den Haag, Nederland

\section{S. van der Harst}

Organisatie 'Jong Florence' (inmiddels CJG Den Haag), Den

Haag, Nederland tijd van 3 jaar (primair) is gericht, werd bij 9 kinderen van de 101 verwezen kinderen gevonden. Bij $57 \%$ van deze 101 kinderen werd 'een of andere oogafwijking' gevonden, maar meestal betrof dat een mogelijke risicofactor voor het ontstaan van amblyopie. De huidige APK-kaart wordt volgens professionals niet geheel gebruikt zoals bedoeld. De APK leidt tot een relatief groot aantal onterechte verwijzingen. Het VOVonderzoek en de BTV hebben volgens dit onderzoek geen ondersteunende of aanvullende waarde bij het visusonderzoek met de APK.

Conclusie De APK-test wordt niet altijd volgens de richtlijn uitgevoerd en resulteert in een groot aantal afwijkende uitslagen en onnodige verwijzingen. Bij de groep kinderen met een afwijkende APK was de VOV evenals de BTV niet voorspellend voor één of andere oogafwijking.

Trefwoorden amblyopie · visusscreening - Amsterdamse Plaatjes Kaart (APK) · Vroegtijdige Opsporing van Visuele Stoornissen (VOV) • Brückner Test Variant (BTV)

\section{Inleiding}

Amblyopie komt voor bij ongeveer 3 tot $4 \%$ van de populatie [1]. In Nederland worden kinderen op verschillende leeftijden gescreend om belangrijke oogafwijkingen op te sporen. Op de leeftijd van 36 maanden (3 jaar) wordt de visus gemeten met de Amsterdamse Plaatjes Kaart (APK) [2]. Wanneer het resultaat afwijkend is voert de jeugdarts een Vroegtijdige Opsporing van Visuele Stoornissen (VOV) onderzoek uit [3]. Conform de huidige jeugdgezondheidszorg (JGZ) richtlijn Opsporing visuele stoornissen worden kinderen teruggezien na 1 tot 3 maanden, dan wel verwezen naar het ziekenhuis voor verder oogheelkundig onderzoek [3]. Als kinderen worden teruggezien na 
1 tot 3 maanden bestaat het herhalingsonderzoek uit de APK-test in combinatie met het VOV-onderzoek. Een afwijkende uitslag bij het VOV-onderzoek kan de verwijzing ondersteunen. Kinderen worden echter bij een afwijkende APK-testuitslag bij het herhalingsbezoek altijd verwezen voor verder onderzoek, onafhankelijk van de uitslag van het VOV-onderzoek.

De VOV-methode is uitgebreid onderzocht in een grote observationele studie (Rotterdam Amblyopia Screening Effectiveness Study: RAMSES) [1]. De VOV duurt echter langer dan een minuut om uit te voeren en vergt volledige medewerking van het kind. Een mogelijk alternatief oogonderzoek als aanvulling op de APK-test in de JGZ zou de Brückner Test Variant (BTV) kunnen zijn [4]. De BTV-methode kost ongeveer 10 seconden en de medewerking van het kind is niet noodzakelijk; dit maakt dat de BTV-methode door tijdsbesparing financieel aantrekkelijk kan zijn, en het mogelijk een praktisch makkelijker alternatief voor de VOV is [4].

De aanleiding voor dit onderzoek is dat het niet bekend is wat de opbrengst is van het visusonderzoek van 3-jarigen in de JGZ en hoe het wordt uitgevoerd. In de regio Den Haag voerden wij een kortdurend onderzoek uit om de volgende vragen te beantwoorden:

1. Hoeveel kinderen worden (onterecht) verwezen naar aanleiding van het visusonderzoek met de APK op de leeftijd van 3 jaar?

2. Kan (aanvullend gebruik van) het VOV-onderzoek en/of de BTV onterechte verwijzingen (bij het APKonderzoek) naar het ziekenhuis voorkomen?

3. Hoe worden kinderen voorbereid op het visusonderzoek met de APK en hoe wordt de test uitgevoerd?

\section{Methoden}

Tussen oktober 2013 en januari 2014 vond er een cohortstudie plaats van alle driejarige kinderen die een JGZ-visusonderzoek kregen in Den Haag, bij de organisatie Jong Florence (inmiddels Centrum Jeugd en Gezin Den Haag).

Voorafgaand aan de studie werden alle jeugdartsen en jeugdverpleegkundigen geïnformeerd over het onderzoek en werd er een inventarisatie gemaakt met betrekking tot de mogelijke redenen voor een abnormale (afwijkende of twijfelachtige uitslag; zie beschrijving van de onderzoeksmethode) APK-testuitslag. Voor het opgeven van mogelijkheden werd een formulier met een keuzelijst opgenomen in het digitaal dossier van de JGZ. De mogelijkheden in de keuzelijst waren: slecht materiaal, kindgebonden factoren (concentratie), oudergebonden factoren (ouderlijke invloed, oefening) en logistieke factoren (tijd). Alle jeugdverpleegkundigen vulden ook een formulier in over de manier van uitvoeren van de APK-test.

De jeugdartsen volgden een twee uur durende training in het uitvoeren van de BTV.
Alle kinderen met een afwijkende APK-testuitslag bij de jeugdverpleegkundige ondergingen een VOVonderzoek en BTV door de jeugdarts, voordat zij werden verwezen naar het ziekenhuis voor oogheelkundig onderzoek. Bij de verwijsbeslissing werd geen rekening gehouden met de uitslagen van het VOV-onderzoek en de BTV. Het oogheelkundig onderzoek in het ziekenhuis bestond uit orthoptisch onderzoek, visusbepaling (APK/E-haken), objectieve refractie (skiascopie) en fundoscopie in cycloplegie. Het resultaat van het oogheelkundig onderzoek in het ziekenhuis werd in dit onderzoek beschouwd als 'gouden standaard' en de uitslagen werden opgenomen in het digitaal kind dossier van de JGZ.

De volgende oogafwijkingen werden geregistreerd: (1) amblyopie, (2) strabismus, (3) myopie, (4) hypermetropie en (5) astigmatisme. De laatste vier afwijkingen zijn een (mogelijke) oorzaak van een verminderde visus. Vanaf hier zal gesproken worden over 'een of andere oogafwijking' als er een oogafwijking vastgesteld is, zonder dat bekend is over welk van de bovenstaande oogafwijkingen het gaat.

\section{Beschrijving van de onderzoeksmethoden}

Amsterdamse Plaatjes Kaart test

Met de APK-test werd de monoculaire visus bepaald. De APK is niet logaritmisch en gebruikt geen gestandaardiseerde optotypen. Een normale APK-testuitslag is $5 / 5$ (als fractie genoteerd), wat vergelijkbaar is met 0,5 op de Snellenkaart (een gestandaardiseerde letterkaart). In dit onderzoek was bij het onderzoek in de JGZ sprake van een afwijkende uitslag (dat wil zeggen: verdenking op amblyopie) wanneer de score $\leq 5 / 15$ was in het slechtste oog, of wanneer er een verschil was van minimaal twee regels tussen de ogen. Er was sprake van een twijfelachtige uitslag (dat wil zeggen: twijfel aan de verdenking op amblyopie) wanneer de score $5 / 10$ of 5/6 was in het slechtste oog, of wanneer er een verschil was van een regel tussen de ogen [1].

Aangezien in dit onderzoek alle kinderen met een afwijkende of twijfelachtige APK-testuitslag werden verwezen, worden zowel 'afwijkende' als 'twijfelachtige' uitslagen beschouwd als 'afwijkend' bij de verdere analyses.

\section{Vroegtijdige Opsporing van Visuele Stoornissen onderzoek}

Voor de VOV werden de volgende activiteiten uitgevoerd: inspectie van het oog, pupil en pupilreacties, cornealichtreflex, afdektest, oogbewegingen en de pupillichtreflex [5]. Verminderde visus en zogenaamde 'afweer' van elk oog apart werd ingeschat door de monoculaire oogbewegingen te beoordelen [4]. Opgemerkt moet worden dat de beoordeling van de binoculaire (beide ogen samen) volgbewegingen onderdeel is van het van Wiechen onderzoek (een breed ontwikkelingsonderzoek). Een kind moet echter een zeer sterk verminderde visus hebben (bijna blind zijn) 


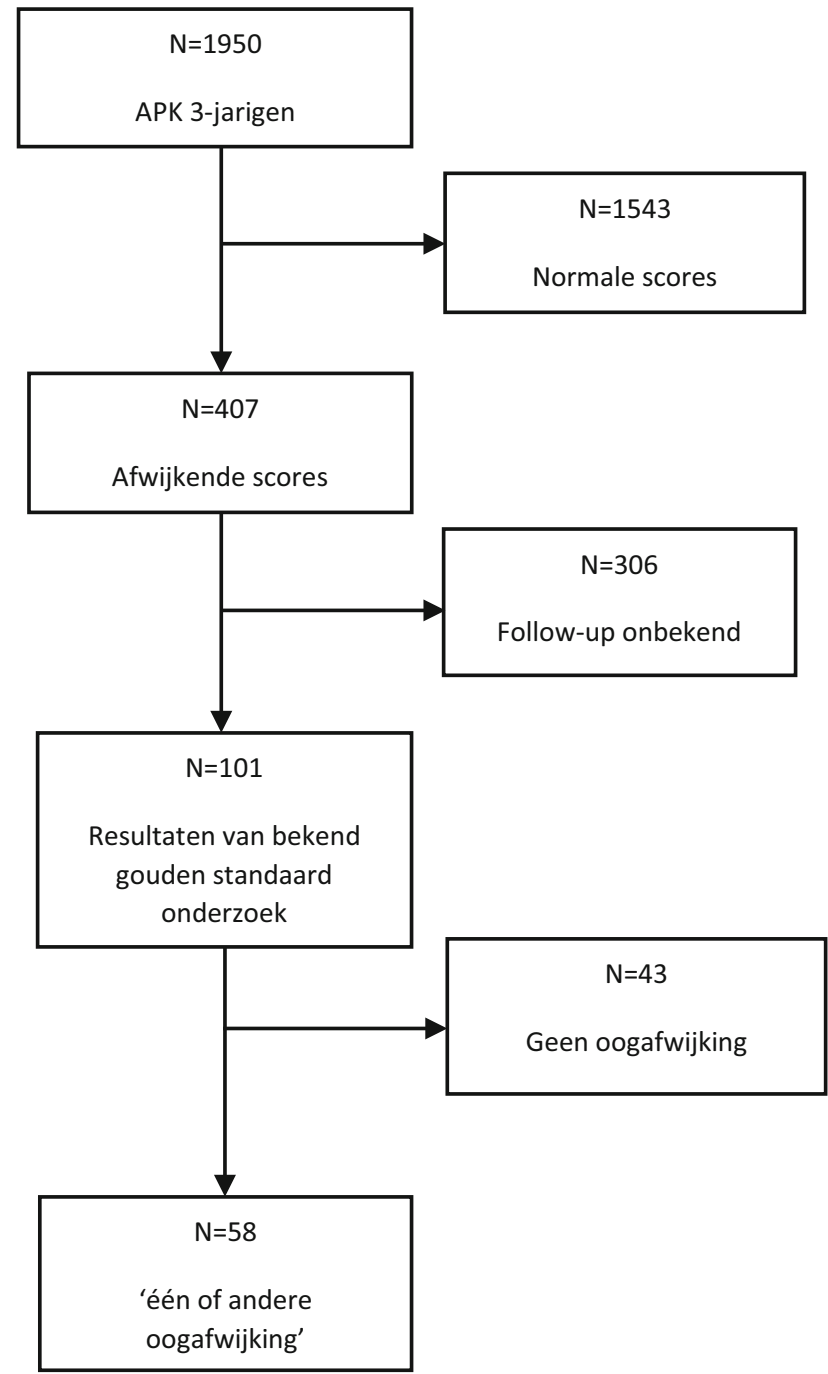

Figuur 1 Flowchart van de driejarigen die een oogheelkundig onderzoek (gouden standaard onderzoek) in het ziekenhuis kregen

of een ernstige beperking van de oogmotoriek hebben, voordat het geen binoculaire volgbewegingen kan maken.

\section{Brückner Test Variant}

De rode reflex van beide ogen werd onderzocht op een afstand van 30 centimeter. Door dit onderzoek via opeenvolgende bewegingen tussen beide ogen te doen was het mogelijk om een verschil in kleur en helderheid te beoordelen. Beide ogen werden ook beoordeeld op een afstand van 1 meter [6]. Maanvorming in de bovenste helft van de pupil kan een teken zijn van hypermetropie, maanvorming onderaan kan een teken zijn van myopie, en maanvorming in andere hoeken kan een teken zijn van een cilinderafwijking (astigmatisme) [4].

\section{Resultaten}

Er namen 1950 driejarigen deel aan het onderzoek. Van deze 1950 kinderen hadden er 407 (21\%) bij het reguliere onderzoek door de jeugdverpleegkundige een afwijkende APK-testuitslag, waarvoor verwijzing plaatsvond. De resultaten van het oogheelkundige onderzoek in het ziekenhuis waren bekend voor 101 kinderen (fig. 1). Van deze 101 naar het ziekenhuis verwezen kinderen waren er 71 verwezen met een 'twijfelachtige' uitslag en 30 met een 'afwijkende' uitslag van de APK-test.

\section{Amsterdamse Plaatjes Kaart test}

Van de 71 kinderen met een 'twijfelachtige' uitslag van de APK-test hadden er 39 een of andere oogafwijking (55\%). Van de 30 kinderen met een 'afwijkende' uitslag van de APK-test hadden er 19 (63\%) één of andere oogafwijking. Er was geen significant verschil tussen de twee groepen ( $p=0,512$ ). In totaal hadden dus 58 kinderen met een 'afwijkende' of 'twijfelachtige' APK-testuitslag een of andere oogafwijking (57\% van de 101 verwijzingen): negen van deze kinderen hadden amblyopie; 49 hadden geen amblyopie maar hadden een risicofactor voor het ontstaan van amblyopie (dat zijn de zogenaamde amblyogene factoren: vier kinderen hadden strabismus, vier myopie, 21 astigmatisme, 22 hypermetropie; twee kinderen hadden meerdere amblyogene factoren).

Bij 193 van de 407 kinderen werd door jeugdverpleegkundigen genoteerd waarom er naar hun mening sprake was van een verwijzing naar het ziekenhuis na het APK-onderzoek (tab. 1). De meest genoteerde reden voor een abnormale APK-testuitslag was dat het kind de symbolen niet kon zien (61\%). Daarna was een verminderde concentratie (30\%) de meest genoteerde reden. De verpleegkundigen kozen andere redenen dan het 'niet kunnen zien' voor een afwijkende APK-testuitslag bij $39 \%$ van de gevallen.

\section{Uitvoering APK-test}

Er werden 26 vragenlijsten verzameld over de instructies die de jeugdverpleegkundigen gaven aan de kinderen en ouders met betrekking tot de APK-test.

Er werd door 25 jeugdverpleegkundigen antwoord gegeven op de vraag of er vooraf aan het consult geoefend was. Door 23 van de 25 jeugdverpleegkundigen (92\%) werd genoteerd dat ze hadden gevraagd of het kind had geoefend. Meerdere jeugdverpleegkundigen oefenden ook met de voorbeeldplaatjes in de groeigids om te verifiëren of het kind de symbolen kende ( $n=20,80 \%$ ). Een aantal jeugdverpleegkundigen liet het kind oefenen op een korte afstand, zonder bril $(n=$ $3,12 \%)$. De symbolen die het meest door de 26 verpleegkundigen gebruikt werden bij de uitvoering van de test waren de auto, eend, kat en laars. De vaas en sleutel werden het minst gebruikt (tab. 2). 
Tabel 1 Mogelijke redenen voor een abnormale APKuitslag gebaseerd op de indruk van de jeugdverpleegkundigen bij 193 kinderen: aantal en \% tussen haakjes

\begin{tabular}{|l|l|}
\hline Reden genoteerd bij een abnormale APK-uitslag & $n(\%$ van 193) \\
\hline Kan het niet zien & $117(61)$ \\
\hline Verminderde concentratie & $57(30)$ \\
\hline Verlegen & $25(13)$ \\
\hline Kan symbolen niet herkennen & $17(9)$ \\
\hline Niet geoefend & $16(8)$ \\
\hline Niet meewerkend & $16(8)$ \\
\hline Matig taalgebruik & $15(8)$ \\
\hline Jonge indruk & a \\
\hline Jong qua leeftijd & $10(5)$ \\
\hline Negatieve invloed van de ouder & $4(2)$ \\
\hline Onbetrouwbaar (ouders antwoorden) & $4(2)$ \\
\hline Jonge indruk & $3(2)$ \\
\hline $\begin{array}{l}\text { a Jonge indruk, van Wiechen ontwikkelingsscores normaal } \\
\text { bJonge indruk, van Wiechen ontwikkelingsscores abnormaal }\end{array}$ \\
\hline
\end{tabular}

Tabel 2 Symbolen van deAPK die gebruikt werden doorde jeugdverpleegkundigen van de organisatie

\begin{tabular}{|l|l|}
\hline & Gebruikte symbolen $(N=26)$ \\
\hline Auto & 26 \\
\hline Eend & 26 \\
\hline Kat & 26 \\
\hline Laars & 26 \\
\hline Huis & 25 \\
\hline Vlag & 25 \\
\hline Klok & 24 \\
\hline Ketel & 21 \\
\hline Hond & 20 \\
\hline Vaas & 3 \\
\hline Sleutel & 2 \\
\hline
\end{tabular}

Acht jeugdverpleegkundigen gaven aan dat de kinderen op hun locatie geen Nederlands spraken. Drie jeugdverpleegkundigen vulden de vraag over kennis van de Nederlandse taal niet in.

\section{Vroegtijdige Opsporing van Visuele Stoornissen onderzoek en Brückner Test Variant}

De VOV-testuitslag van de jeugdarts was geregistreerd bij 79 van de 101 kinderen die in het ziekenhuis een uitgebreid oogonderzoek ondergingen (78\%). Van deze kinderen hadden er 45 een of andere oogafwijking. Van de 45 kinderen bij wie in het ziekenhuis een of andere oogafwijking werd vastgesteld, hadden er drie een abnormale VOV-testuitslag. Van de 34 kinderen bij wie in het ziekenhuis geen enkele oogafwijking werd vastgesteld, hadden er twee een afwijkende VOV-testuitslag. In dit onderzoek, op basis van de bovenstaande cijfers, was de specificiteit van de VOV-test dus $94 \%$ (95\% CI 79-99\%), en was de sensitiviteit 6,7\% (95\% CI 2-19\%). Op een andere manier gezegd, in deze specifieke subgroep van kin- deren die allemaal een afwijkende APK hadden, was een afwijkende VOV dus niet voorspellend voor het bestaan van een of andere oogafwijking.

De BTV-uitslag van de jeugdarts was geregistreerd bij 88 van de 101 kinderen die in het ziekenhuis een uitgebreid oogonderzoek ondergingen. Van deze 88 kinderen hadden er 51 een of andere oogafwijking. Van de 51 kinderen bij wie in het ziekenhuis een of andere oogafwijking werd vastgesteld, hadden 26 een afwijkende BTV-uitslag. Van de 32 kinderen bij wie in het ziekenhuis geen enkele oogafwijking werd vastgesteld hadden er 10 een afwijkende BTV-testuitslag. De specificiteit van de BTV was $59 \%$ (95\% CI 42-75\%) en de sensitiviteit was $51 \%$ (95\% CI 37-65\%). De BTV-uitslag was dus evenmin voorspellend voor het bestaan van één of andere oogafwijking bij kinderen met een afwijkende APK.

\section{Discussie}

In dit onderzoek is specifiek gekeken naar de positief voorspellende waarde van een afwijkende uitslag van de APK-test in de JGZ op de leeftijd van 3 jaar, wanneer er wordt gekeken naar de uitslag van een uitgebreid oogonderzoek in het ziekenhuis als gouden standaard. Het bleek dat van de 101 kinderen over wie we gegevens van het oogheelkundige onderzoek in het ziekenhuis hadden, er bij $57 \%$ een of andere oogafwijking was vastgesteld. Echter, bij slechts 9 van de 101 kinderen werd amblyopie vastgesteld; bij de andere kinderen met een oogafwijking betrof het factoren die mogelijk bijdragen aan het ontstaan van amblyopie.

In deze studie kon de prevalentie van amblyopie en van andere oogafwijkingen niet worden vastgesteld omdat alleen kinderen met een afwijkende test zijn verwezen. Van alle in de JGZ onderzochte kinderen had $21 \%$ een afwijkende APK-uitslag, maar slechts van een op de vier is het resultaat van het oogonderzoek in het ziekenhuis bekend. De gegevens over het oogonderzoek in het ziekenhuis hebben dus alleen betrekking op een mogelijk selecte subgroep van alle verwezen kinderen. In dit onderzoek werden oogafwijkingen zoals vastgesteld in het ziekenhuis geclassificeerd als aanwezig of afwezig, terwijl er varianten zijn in de ernst van de afwijking. In de analyses is geen onderscheid gemaakt tussen het aanwezig zijn van amblyopie of van een andere oogafwijking. We bevelen aan om in toekomstig onderzoek met grotere onderzoeksgroepen, de soorten oogafwijkingen en de ernst ervan goed te registreren en te betrekken in de analyses.

Er was geen significant verschil ten aanzien van het vaststellen van een oogafwijking in het ziekenhuis tussen kinderen met een 'afwijkende' uitslag en een 'twijfelachtige' uitslag van de APK in de JGZ. In de toekomst zou daarom moeten worden nagegaan of het wel zinvol is om dit onderscheid te maken; zou het bijvoorbeeld meer kosteneffectief zijn om ook de kin- 
deren met een 'afwijkende' APK terug te laten komen voor een herhalingsonderzoek?

Kinderen krijgen voldoende kans om voorbereid te worden op de APK, maar hier wordt niet altijd gebruik van gemaakt. Ouders hebben de mogelijkheid om de symbolen te oefenen met behulp van de groeigids, waarin de persoonlijke groei en ontwikkeling van het kind kan worden bijgehouden. Daarnaast is op de website van de organisatie in Den Haag een uitleg van de visustest met een link naar een YouTube film beschikbaar [7].

Op een aantal locaties in Den Haag ontvangen ouders plaatjes van de symbolen samen met de uitnodiging om te kunnen oefenen en zich te kunnen voorbereiden op het consult. Bij kinderen van wie de ouders de Nederlandse taal niet machtig zijn zal het oefenen misschien minder vaak gebeuren. Wat betreft het juiste gebruik van de APK-visuskaart werd gevonden dat niet alle symbolen worden gebruikt door de professionals, mogelijk doordat bepaalde voorwerpen verouderd zijn en niet bekend zijn bij kinderen. Vaak worden dezelfde symbolen gebruikt. Vanwege een beperkte keuze zou de test minder valide kunnen zijn.

Een alternatief voor de APK zou de Lea-Hyverine kaart (die ook gebruikt wordt in België) kunnen zijn $[8,9]$. Deze kaart wordt in Nederland nu al gebruikt bij kinderen met een verstandelijke beperking [10].

Deze studie heeft een aantal beperkingen. De kinderen met een normale APK-testuitslag kregen geen uitgebreid oogonderzoek in het ziekenhuis ('gouden standaard'). Daarom is het niet bekend of er van de kinderen met een 'normale APK-testuitslag', toch een gedeelte amblyopie of andere oogafwijkingen heeft.

Slechts van ongeveer $25 \%$ van de verwezen kinderen was het resultaat van het uitgebreide oogonderzoek in het ziekenhuis bekend. Dit kan zowel komen door het niet gebruik maken van de verwijzing, als door onvoldoende terugkoppeling van de resultaten vanuit het ziekenhuis. Landelijke onderzoeksresultaten laten zien dat $23-33 \%$ van de ouders niet met het kind naar het ziekenhuis gaat [11, 12].

Binnen de subgroep kinderen met een 'afwijkende' of 'twijfelachtige' APK-uitslag hadden zowel de VOV als de BTV geen relevante (aanvullende) voorspellende waarde voor 'één of andere oogafwijking' (amblyopie, strabismus, myopie, hypermetropie of astigmatisme) vastgesteld bij onderzoek in het ziekenhuis. Er moet echter opgemerkt worden dat de onderzoeksgroep in deze studie relatief klein was. Toekomstig onderzoek zou gebruik moeten maken van grotere onderzoeksgroepen. Ook is daarbij aandacht nodig voor een goede training van de JGZ-professionals ten aanzien van het VOV-onderzoek en de BTV [13]. Om het gebruik van het VOV-onderzoek en de BTV in de hele populatie te onderzoeken (dus niet alleen bij kinderen met een afwijkende APK) is een apart onderzoek nodig.

\section{Conclusie}

Concluderend heeft $21 \%$ van de driejarigen een afwijkende APK-testuitslag. In de studie was slechts bij 1 op de 4 verwijzingen een uitslag van het oogonderzoek in het ziekenhuis bekend. Amblyopie, de aandoening waarop het onderzoek in de JGZ op de leeftijd van 3 jaar primair is gericht, werd bij 9 van de 101 verwezen kinderen waarvan de resultaten van het oogonderzoek in het ziekenhuis beschikbaar waren, gevonden. Bij $57 \%$ van deze 101 kinderen werd 'een oogafwijking' gevonden, maar meestal betrof dat een mogelijke risicofactor voor het ontstaan van amblyopie. De richtlijn voor opsporing van oogafwijkingen binnen de JGZ wordt op dit moment herzien en de resultaten van deze studie kunnen daarbij worden gebruikt. De huidige APK wordt volgens professionals niet altijd gebruikt zoals bedoeld. De APK leidt tot een relatief groot aantal onterechte verwijzingen. Het VOV-onderzoek en de BTV hebben volgens dit onderzoek geen ondersteunende, aanvullende waarde bij het onderzoek met de APK.

Dankbetuiging De auteurs bedanken P. van Dommelen en P.H. Verkerk (TNO) voor het kritisch lezen van dit stuk en het geven van statistisch advies. Ook worden M. Groeneveld en M. Verhaag (CJG den Haag, voorheen Jong Florence) bedankt voor het data management.

Financiering Deze studie werd ondersteund door ZonMw (grant nummer 2015000036).

\section{Literatuur}

1. GroenewoudJH,TjiamAM,LantauVK, etal. RotterdamAMblyopiascreeningeffectiveness study: detection and causes of amblyopia in a large birth cohort. Invest Ophthalmol Vis Sci. 2010;51(7):3476-84.

2. Donkers ECMM. Oogheelkundige screening bij kinderen. Assen: Uitgeverij Van Gorcum; 1998. pag. 85.

3. Coenen-van Vroonhoven ECJLV, Eerdenburg-Keuning IA van, Velzen-Mol HWM van. Opsporing visuele stoornissen. Utrecht: Nederlands Centrum Jeugdgezondheid; 2010.

4. Iyer V, Samkar A van, Saeed P. The Bruckner test variant (BTV): a promising instrument in detecting vision disorders. Am Orthopt J.2013;63:97-102.

5. Velzen-Mol HW van, Blankespoor MN, Wagenaar-Fischer MM, Leerdam FJ van. The guideline 'Detection of visual disorders at the age of $0-19$ ' from the Dutch Association of Child Health Care. Ned Tijdschr Geneeskd. 2003;147(41):2012-7.

6 . Waltermann J. Improving vision screening in kids. Medscape2015. 2015. http://www.medscape.com/features/ slideshow/vision- screen. Geraadpleegd op: 1stjuly 2015.

7. Jong-Florence. De oogtest - instructie [Movie]. 2012. https://www.youtube.com/watch?v=I0_hSkvkjmc. Geraadpleegd op: 1stjuly 2013.

8. Chui L, Fraser T, Hoar K, LaRoche GR. Negative predictive value of a vision screening program aimed at children aged 3 to 4 years old. JAAPOS. 2004;8(6):566-70.

9. Sloot F, Hoeve HL, Kroon M de, Goedegebure A, Carlton J, Griffiths HJ, et al. Inventory of current EU paediatric vision and hearing screening programmes. J Med Screen. 2015;22(2):55-64. 


\section{Onderzoeksartikel}

10. Lai YH, Wang HZ, Hsu HT. Development of visual acuity in preschool children as measured with Landolt $\mathrm{C}$ and Tumbling E charts. JAAPOS. 2011;15(3):251-5.

11. Juttmann RE, Koning HJ de, Meulmeester JF, Maas PJ van der. Published effects of screening in parental and child health care. Ned Tijdschr Geneeskd. 1996;140(25):1303-7.

12. Tjiam AM, Groenewoud JH, Passchier J, Loudon SE, De Graaf M, Hoogeveen WC, et al. Determinants and outcome of unsuccessful referral after positive screening in a large birth-cohort study of population-based vision screening. JAAPOS. 2011;15(3):256-62.

13. SlootF, Sami A, Karaman H, Benjamins J, LoudonSE, RaatH, et al. Effect of omission of population-based eye screening at age 6-9 months in the Netherlands. Acta Ophthalmol. 2014;93(4):318-21.

V. Iyer, arts Maatschappij \& Gezondheid

A. van Samkar, arts-onderzoeker

E. Vlasblom, psycholoog-onderzoeker

H.M. van Minderhout, orthoptist-onderzoeker

S. van der Harst, arts Maatschappij \& Gezondheid 